\title{
Control of Flowering in Strawberries
}

\author{
Koskela, Elli A.
}

Springer International Publishing AG

2018

Koskela , E A \& Hytonen , T 2018, Control of Flowering in Strawberries . in T Hytonen , J Graham \& R Harrison (eds), GENOMES OF ROSACEOUS BERRIES AND THEIR WILD RELATIVES . Compendium of Plant Genomes, Springer International Publishing AG, GEWERBESTRASSE 11, CHAM, CH-6330, SWITZERLAND , pp. 35-48 . https://doi.org/10.1007/978-3-319-76020-

http://hdl.handle.net/10138/309926

https://doi.org/10.1007/978-3-319-76020-9

unspecified

acceptedVersion

Downloaded from Helda, University of Helsinki institutional repository.

This is an electronic reprint of the original article.

This reprint may differ from the original in pagination and typographic detail.

Please cite the original version. 


\title{
1 Control of flowering in strawberries
}

\section{Elli A. Koskela and Timo Hytönen}

Department of Agricultural Sciences, Viikki Plant Science Centre, P.O.Box 27, 00014 University of Helsinki, Finland

Corresponding author email: timo.hytonen@helsinki.fi

\begin{abstract}
Strawberries (Fragaria sp.) are small perennial plants capable of both sexual reproduction through seeds and clonal reproduction via runners. Because vegetative and generative developmental programs are tightly connected, the control of flowering is presented here in the context of the yearly growth cycle. The rosette crown of strawberry consists of a stem with short internodes produced from the apical meristem. Each node harbors one trifoliate leaf and an axillary bud. The fate of axillary buds is dictated by environmental conditions; high temperatures and long days (LDs) promote axillary bud development into runners, whereas cool temperature and short days (SDs) favor the formation of branch crowns. SDs and cool temperature also promote flowering; under these conditions, the main shoot apical meristem is converted into a terminal inflorescence, and vegetative growth is continued from the uppermost axillary branch crown. The environmental factors that regulate vegetative and generative development in strawberries have been reasonably well characterised, and are reviewed in the first two chapters. The genetic basis of the physiological responses in strawberries is much less clear. To provide a point of reference for the flowering pathways described in strawberries so far, a short review on the molecular mechanisms controlling flowering in the model plant Arabidopsis is given. The last two chapters will then describe the current knowledge on the molecular mechanisms controlling the physiological responses in strawberries.
\end{abstract}

\subsection{The yearly growth cycle}

Strawberries are small perennial plants that reproduce both sexually through seeds and clonally via runners. Strawberry stem is called rosette crown that consists of short internodes produced from the apical meristem. Each node harbors one trifoliate leaf and an axillary bud. Axillary buds may develop into runners, which are elongated stems with two long internodes followed by a daughter plant, into axillary leaf rosettes called branch crowns, or remain dormant. The apical meristem may keep on producing new nodes or develop into a cymose inflorescence. When the apical meristem turns into an inflorescence meristem, the uppermost axillary bud develops into a branch crown that sustains vegetative growth in a sympodial fashion (Figure 1.1.1; Darrow 1966).

The fate of the apical and axillary meristems is dictated by seasonal changes in photoperiod and temperature. During the summer months, strawberries grow vegetatively and axillary buds differentiate into runners. In autumn, axillary buds develop into branch crowns instead of runners, and the apical meristems of the main crown and bigger branch crowns form terminal inflorescences. Short days (SDs) in autumn also cause an overall halt in vegetative development, and the plants enter a state of semi-dormancy characterised by shorter petiole length and stunted growth (Sønsteby and Heide 2011). Winter chilling is needed to break this dormant state, and in the following spring, inflorescences initiated the preceding autumn complete their development, and the next seasonal cycle follows (Figure 1.1.1; Darrow 1966).

The seasonal growth cycle described above holds true for both the diploid woodland strawberry Fragaria vesca (L.), and its cultivated octoploid relative Fragaria $\times$ ananassa (Duch.), although exceptional environmental responses have been described in both species (Chapter 1.2). In both species, flowering is induced in SDs at cool to medium temperatures, and inhibited by long days 
(LDs) and high temperature. Because of the close resemblance of physiological responses, it has long been speculated that the molecular regulatory networks controlling environmental responses may be similar in the two species (e.g. Battey et al. 1998). Indeed, this view recently gained empirical evidence when Koskela et al. (2016) showed that some of the core genes involved in photoperiod and temperature regulated flowering responses function similarly in the two strawberry species. Due to these similarities, it is feasible to present findings on diploid and octoploid strawberry physiology and molecular pathways side-by-side. In some cases, this is also necessary, as physiological responses have been examined at a greater depth in octoploid than in diploid strawberries, while molecular studies into flowering regulation have mostly focused on the diploid $F$. vesca.
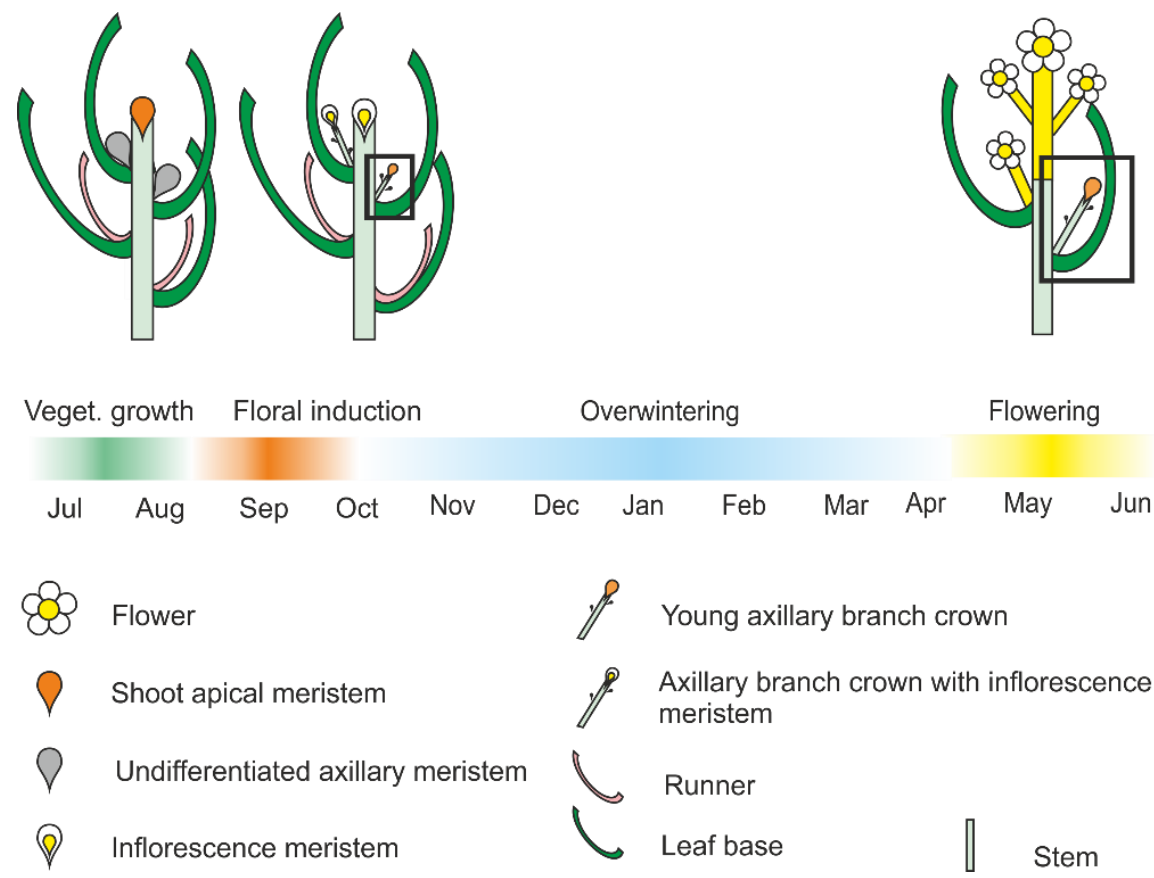

Figure 1.1.1. Plant structure and typical seasonal growth cycle of strawberries grown in temperate zone. During the summer months, strawberries grow vegetatively and axillary buds produce runners, whereas in autumn, young axillary buds differentiate into branch crowns. Floral induction occurs in autumn, and apical meristems of main and branch crowns develop into inflorescence meristems. Inflorescence development is completed in the following spring and summer when plants flower and produce fruits. The axillary buds that were too young to be induced to flower the preceding autumn (highlighted with black rectangles) grow out as new branch crowns, thus completing the perennial life cycle.

To understand flowering, i.e. generative development, it is important to comprehend vegetative development. These two processes are often interrelated; for instance, the number of floweringcompetent apical meristems in strawberry depends on the number and age of branch crowns on the plant, and the timing of branch crown formation (Hytönen et al. 2004). Because of the interdependency between vegetative and generative development, this review aims to give a thorough picture of the effects that the seasonally changing environment imposes on the yearly growth cycle of strawberries. The latter chapters will then describe the current knowledge on the molecular mechanisms controlling these physiological responses.

\subsubsection{Summer}

Long days and high temperature during summer promote vegetative development, i.e. the differentiation of axillary buds into runners. Vegetative vigor is also manifested by increased petiole length (Sønsteby and Nes 1998; Heide and Sønsteby 2007). The wild diploid strawberry accessions studied to date stay in the vegetative stage when the daylength exceeds 16-17 hours (Heide and Sønsteby 2007). However, the studied accessions originate from Norway, where the days are very long during summer. It is quite likely that more Southern accessions continue vegetative development under shorter photoperiods. 
High temperatures of above $17-20^{\circ} \mathrm{C}$ are considered optimal for runner production (Battey et al. $1998)$. Indeed, when diploid strawberry is subjected to cool temperature $\left(11^{\circ} \mathrm{C}\right)$, runner production ceases within a few weeks (Figure 1.1.1.1). Also in cultivated strawberry, 16-hour photoperiod and temperatures above 18 to $24^{\circ} \mathrm{C}$ enhance both runner formation and petiole elongation (Heide 1977; Bradford et al., 2010), although different cultivars may exhibit significant differences both in their overall runnering capacity and in their responses to photoperiod (Sønsteby and Nes 1998). On the other hand, SDs strongly suppress runner formation in most studied octoploid strawberry cultivars and also in the octoploid progenitor species F. virginiana and F. chiloensis (Serçe and Hancock 2005; Bradford et al. 2010).

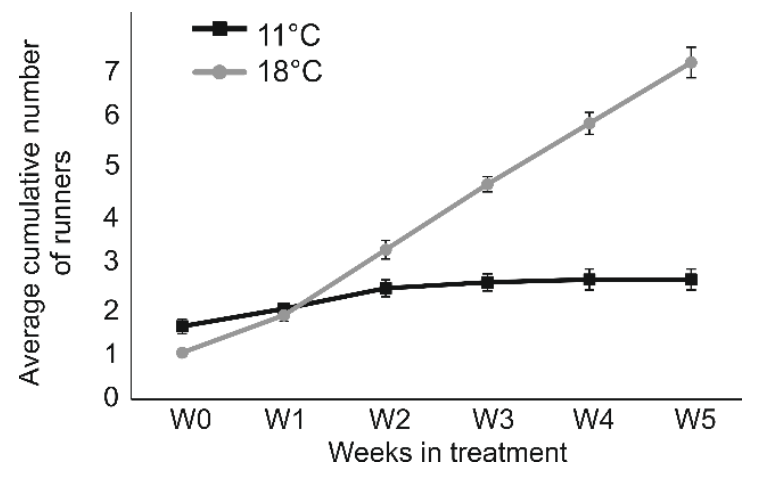

Figure 1.1.1.1. Average cumulative number of runners at different temperatures. Runner-propagated plants of seasonal flowering $F$. vesca were grown in LDs at either $11^{\circ} \mathrm{C}$ or $18^{\circ} \mathrm{C}$ for five weeks. Error bars denote the standard error of the mean $(\mathrm{n}=16$ and 10 for $11^{\circ} \mathrm{C}$ and $18^{\circ} \mathrm{C}$ treatments, respectively).

\subsubsection{Autumn}

As the days get shorter and temperature lower towards autumn, runner formation ceases and the uppermost axillary buds develop into branch crowns. A prolonged exposure to SDs and/or cool temperature induces flowering, and the shoot apical meristem develops into an inflorescence meristem. Also the apical meristems of the oldest branch crowns may form inflorescences, while the younger branch crowns remain vegetative and continue the typical life cycle of a perennial plant during the next growing season (Hytönen et al. 2004; Albani and Coupland 2011).

In the diploid strawberry, flower induction is triggered by integration of photoperiodic and temperature signals. Temperature is perhaps the more important factor, as it sets the limits for photoperiod-induced flowering. In most $F$. vesca accessions, high temperature $\left(>21^{\circ} \mathrm{C}\right)$ inhibits flowering under all photoperiods, whereas cool temperature $\left(10^{\circ} \mathrm{C}\right)$ induces flowering photoperiodindependently. At intermediate temperatures $\left(13-18^{\circ} \mathrm{C}\right)$, flowering is promoted by SD conditions (Heide and Sønsteby, 2007; Rantanen et al. 2015). Because of the strong interaction between temperature and photoperiod, the critical photoperiod for flower induction varies depending on temperature. At $15^{\circ} \mathrm{C}$, the critical photoperiod is between 16 to 17 hours, whereas at $18^{\circ} \mathrm{C}$ photoperiods shorter than 16 hours are required to induce flowering (Heide and Sønsteby 2007; Rantanen et al. 2015). The wild strawberry accessions studied so far require at least four weeks of inductive light conditions for floral induction, with a longer exposure resulting in more rapid flowering (Heide and Sønsteby 2007). However, our results indicate that flower induction occurs earlier at cool temperatures (E. Koskela, T. Tuomainen and T. Hytönen, unpublished).

Seasonally flowering octoploid strawberry cultivars show a similar trend in their flowering responses to environmental conditions, although the critical temperatures and photoperiods vary from cultivar to cultivar. In most cultivars, flowering is inhibited by high temperatures of above $22^{\circ} \mathrm{C}$, and cool temperatures $\left(10-12^{\circ} \mathrm{C}\right)$ induce flowering independently of the photoperiod. At intermediate temperature range flowering is promoted by SDs (Heide 1977; Bradford et al., 2010). The relative importance of the flowering pathways (photoperiod vs. temperature) differs between cultivars; some cultivars respond exclusively to short photoperiod, with no flower induction taking place in LDs even at cool temperature (Sønsteby and Nes 1998; Sønsteby and Heide 2006; Verheul et al. 2007). In other 
cultivars, flowering occurs photoperiod-independently at temperatures as high as $18^{\circ} \mathrm{C}$ (Heide 1977 ; Bradford et al., 2010).

\subsubsection{Winter}

In addition to floral induction, autumnal environmental conditions bring about additional physiological changes in strawberries. An exposure to SDs and mild temperature for an extended period of 10 to 15 weeks has been shown to induce a state of semi-dormancy in both diploid (Sønsteby and Heide 2011) and octoploid strawberries (Darrow and Waldo 1943; Guttridge 1985; Sønsteby and Heide 2006). Semi-dormant plants have shorter petioles and smaller leaves than non-dormant plants and are slow to resume growth when returned to LDs (Jonkers 1965). For example, semi-dormant plants of cultivar Elsanta resumed regular growth vigor after approximately one month in LDs (Lieten 1997).

The most effective dormancy-breaking treatment is subjecting the plants to several weeks of chilling, i.e. temperatures between -2 and $6^{\circ} \mathrm{C}$ (Guttridge 1985). However, the chilling requirement is genotype-specific, and genotypes adapted to higher latitudes have longer periods of dormancy than genotypes adapted to more Southern conditions (Hancock 1999; Sønsteby and Heide 2011). The dormancy-inducing effect of SDs can also be averted by simultaneously subjecting the plants to low temperature at below $6^{\circ} \mathrm{C}$ that constantly counteracts the dormancy-inducing effect of SDs (Lieten 1997; Sønsteby and Heide 2006; Sønsteby and Heide 2011). Dormant strawberries are not only slow to resume growth, but they also have lower pollen fertility, produce more misshapen fruits and lower yield than non-dormant strawberries (Lieten 1997). Therefore, dormancy release by chilling is an important aspect from the point of view of practical crop production, and the progressing global warming may cause problems in the future, especially for growers in areas of mild winters.

\subsubsection{Spring}

Environmental conditions that favor vegetative development also promote inflorescence outgrowth and floral development in spring. According to studies on wild diploid strawberry accessions carried out under controlled conditions, photoperiod in spring has no effect on the number of flowers; however, longer days speed up flower development and thus have a mild promoting effect on the timing of flowering (Heide and Sønsteby 2007). Also in the octoploid strawberry, LDs advance floral development in the spring (Sønsteby and Heide 2007a).

The effect of temperature on the rate of flower and fruit development has not been studied in the diploid strawberry. Experiments with several octoploid strawberry cultivars suggest that warm spring temperatures speed up both flower and fruit development resulting in earlier cropping. However, there is a negative relationship between temperature and total yield; with rising temperature, a smaller proportion of flowers produce fruit, and the average fruit size is also smaller (Le Mière et al. 1998; Manakasem and Goodwin 2001).

\subsection{Exceptional environmental responses in Fragaria}

Although the environmental responses described above hold true for most genotypes of diploid and octoploid strawberries, both species contain genotypes with exceptional responses. One of the best studied exceptional response is the everbearing character, which has been described in both species. Everbearing strawberries are capable of initiating flowers throughout summer, contrasting the seasonal flowering habit of the SD-induced strawberries. Moreover, everbearing strawberries tend to produce less runners than SD strawberries, and many diploid everbearing genotypes do not produce runners at all (Brown \& Wareing 1965).

Flowering in the everbearing diploid strawberry genotypes is promoted by LDs. A study by Mouhu et al. (2009) demonstrated that flowering in the diploid cultivar 'Hawaii-4' occurs earlier under LDs than SDs at $18^{\circ} \mathrm{C}$, and this difference becomes more clear at higher temperature of $22^{\circ} \mathrm{C}$ (Rantanen 
et al. 2014). Similar results were reported by Sønsteby and Heide (2008a), who showed also that LDs are almost obligatory for flower induction at $27^{\circ} \mathrm{C}$ in two reportedly non-runnering diploid strawberry cultivars. Interestingly, the same authors also noted sporadic runner formation in these two cultivars at high temperature.

Everbearing octoploid strawberry cultivars have often been classified either as everbearers or dayneutrals, especially in the older literature. This distinction was based on the origin of the trait; everbearers originate from old cultivars with a LD flowering response, whereas the day-neutral trait is from a more recent introduction of $F$. virginiana ssp. glauca germplasm into the cultivated strawberry (Durner et al. 1984). More recently, it has been shown that both everbearing and dayneutral octoploid strawberries are actually obligatory LD plants at high temperature $\left(27^{\circ} \mathrm{C}\right)$, quantitative $\mathrm{LD}$ plants at intermediate temperatures and day-neutrals only at temperatures below $10^{\circ} \mathrm{C}$ (Nishiyama and Kanahama 2002; Sønsteby and Heide 2007a). It must be noted, however, that true day-neutrality has been described in a population of $F$. virginiana ssp. glauca from Utah which is considered the main source of the everbearing trait in modern-day everbearing cultivars (Sønsteby and Heide 2008b). Therefore, the origin of the photoperiodic response in modern everbearing cultivars is unknown.

Runnering is enhanced by high temperatures in both diploid and octoploid everbearing strawberries (Sønsteby and Heide 2007a; 2008a). The effect of photoperiod is more difficult to interpret, and there seem to be differences between cultivars; some studies have reported that LDs promote runner production in octoploid everbearing cultivars (Manakasem and Goodwin 2001; Bradford et al. 2010), whereas other workers have described SDs to strongly enhance runnering (Sønsteby and Heide 2007b). In a diploid everbearing strawberry accession Hawaii-4, SDs strongly promote runnering (K. Mouhu, S. Samad, E. Koskela and T. Hytönen, unpublished). In general, conditions that do not favor floral induction appear to enhance runner production. In contrast to runner production, everbearing genotypes tend to produce more branch crowns than SD strawberries, thus providing a greater number of crown apical meristems for inflorescence initiation. The higher number of branch crowns produced by everbearing genotypes results in higher yield potential (Camacaro et al. 2002), but on the other hand decreases the number of axillary buds that could develop into runners, which limits their utility for commercial production (Camacaro et al. 2002; Dale et al. 2002; Sønsteby and Heide 2007a; Bradford et al. 2010).

Another exceptional environmental response is the vernalisation requirement characterised in an arctic diploid strawberry accession from Northern Norway. This accession does not flower if exposed to SDs, even when the temperature is as low as $9^{\circ} \mathrm{C}$ (Heide and Sønsteby 2007). The same authors tested also whether this arctic 'Alta' accession could be induced to flower if exposed to $2^{\circ} \mathrm{C}$ for $5-15$ weeks. However, even after a 15 week exposure, only a proportion of the plants (38\%) flowered. It is noteworthy that the 'Alta' accession does flower after overwintering in field conditions, albeit considerably later than the other tested Norwegian accessions (Heide and Sønsteby 2007). These data indicate that the 'Alta' accession requires a prolonged period at exceptionally cold conditions to fulfil the vernalisation requirement. Physiological and molecular characterisation of the accession is underway.

\subsection{Genetics of flowering}

Physiology of flowering is well-studied in strawberries, but the genetic basis of the physiological responses is much less clear. Genetic control of flowering has been most extensively studied in the annual model plant Arabidopsis, in which both endogenous and environmental pathways regulate flowering (Bouché et al. 2016). Although Arabidopsis and strawberry are distantly related, many genetic components that regulate flowering in Arabidopsis have also been identified in strawberry (Mouhu et al. 2009). It is therefore likely that similar genetic mechanisms could control at least some aspects of reproduction in the two species. 


\subsubsection{Genetics of flowering in Arabidopsis}

Arabidopsis in an annual plant in which flowering is promoted by LDs and high temperature. The photoperiodic flowering response in Arabidopsis is controlled by a rhythmic expression output generated by the circadian clock and involving the action of dozens of genes (Bouché et al. 2016). The CCT domain transcription factor CONSTANS $(C O)$ is one of the rhythmically regulated genes and it is required for the LD-induced flowering in Arabidopsis (Putterill et al. 1995; Sawa et al. 2007). At the protein level, CO stability is regulated by light; the protein is rapidly degraded in dark, and thus only $C O$ expressed during the light period leads to accumulation of $C O$ protein (Andrés and Coupland, 2012).

The circadian regulation of $\mathrm{CO}$ is active in leaf vascular tissues, whereas inflorescences are initiated at the shoot apical meristem. The mobile signal linking these tissues is FLOWERING LOCUS T (FT; Koornneef et al. 1991; Corbesier et al. 2007), which is a member of the CETS protein family (CEN, TFL1 and FT; Pnueli et al. 2001). FT expression is upregulated in LDs directly by CO (Tiwari et al. 2010), and the translated FT protein is actively exported from the phloem companion cells to sieve elements and transported to the shoot apex (Liu et al. 2012).

Members of the CETS protein family do not have DNA binding domains, but they do form complexes with other proteins (Yeung et al. 1999; Pnueli et al. 2001). In the shoot apical meristem, FT forms a complex with a bZIP transcription factor FD and 14-3-3 proteins (Pnueli et al. 2001; Abe et al. 2005; Wigge et al. 2005) to upregulate downstream target genes, including the MADS box transcription factor SUPPRESSOR OF OVEREXPRESSION OF CONSTANS 1 (SOC1; Samach et al. 2000) and the meristem identity genes APETALAl (APl; Abe et al. 2005) and FRUITFUL (FUL; Teper-Bamnolker and Samach 2005). The expression of the meristem identity genes is considered a sign of irreversible commitment to flowering (Hempel et al. 1997).

In Arabidopsis, FT is involved also in the ambient temperature regulation of flowering. Changes in ambient temperature have an effect on chromatin conformation at the FT locus, with low temperature making the locus less accessible to transcription factors (Kumar and Wigge 2010). One of these transcription factors is PHYTOCHROME INTERACTING FACTOR4 (PIF4), a bHLH transcription factor that activates $F T$ transcription and promotes flowering in SDs at high temperature (Kumar et al. 2012).

Another pathway that regulates flowering as a response to ambient temperature involves the MADS box transcription factors SHORT VEGATATIVE PHASE (SVP) and FLOWERING LOCUS M (FLM). The floral repressor SVP is degraded at high temperature (Lee et al. 2013). FLM can be spliced in alternative ways in a temperature-dependent manner; at low temperature, the prevailing splice form is the flowering-repressive FLM- $\beta$. Higher temperatures cause an increase in the relative amount of the splice variant FLM- $\delta$, which is impaired in DNA binding (Posé et al. 2013). FLM- $\beta$ and FLM- $\delta$ compete for forming heterodimers with SVP; at low temperature, the most abundant complex is SVP-FLM- $\beta$, which actively prevents flowering. However, at high temperature the prevailing protein complex is SVP-FLM- $\delta$, which cannot bind to DNA and thus cannot repress the expression of the target genes. The de-repressed target genes, including at least SOC1 and possibly $F T$, can therefore promote flowering as a response to high temperature (Lee et al. 2013; Posé et al. 2013).

The shoot apex is a convergence point for both floral promoting and inhibitive factors. One of the factors with a repressing effect on flowering is TERMINAL FLOWER1 (TFL1; Shannon and MeeksWagner 1991), which belongs to the same CETS protein family as FT (Kobayashi et al. 1999). Similarly to FT, also TFL1 is able to form complexes with FD and 14-3-3 proteins (Abe et al. 2005; Wigge et al. 2005; Hanano and Goto 2010; Ho and Weiger 2014). The floral promoting or inhibiting effect of FT or TFL1, respectively, is hypothesized to be caused by differential recruitment of coactivators, possibly TCP transcription factors (Ho and Weigel 2014).

The abovementioned pathways have been characterised in the annual plant Arabidopsis. However, the components of especially the photoperiodic pathway are fairly conserved across land plants. Homologs of $C O$ and $F T$ have been shown to regulate the photoperiodic responses in e.g. the shortday monocot rice (Hayama et al. 2003), and $F T$ homologs seem to have roles as universal floral 
promoters in e.g. cucurbits (Lin et al. 2007), barley (Yan et al. 2006) and many perennial species including poplar (Böhlenius et al. 2006) and apple (Tränkner et al. 2010). There is also some evidence for FT playing a part in ambient temperature responses in e.g. chrysanthemums (Nakano et al. 2013) and Satsuma mandarin (Nishikawa et al. 2007), as in these species the ambient temperature-induced flowering correlates with increased transcription of $F T$-like genes.

\subsubsection{Genetics of flowering in the diploid $F$. vesca}

The molecular control of flowering in the diploid strawberry was truly begun to be deciphered after the publication of the $F$. vesca genome in 2011 (Shulaev et al. 2011). In 2012, two groups independently utilized genetic mapping to show that the switch from a seasonal flowering phenotype to an everbearer is brought about by a small deletion in a gene encoding the strawberry orthologue of TFL1 (FvTFL1; Iwata et al. 2012; Koskela et al. 2012). TFL1 homologs repress flowering in many plants, including the Rosaceae family crop species rose (Iwata et al. 2012), apple (Kotoda et al. 2006) and pear (Freiman et al. 2012).

Also in strawberry, $F v T F L 1$ functions as a floral repressor, whose downregulation is required for floral induction (Koskela et al. 2012). FvTFL1 expression responds to both photoperiod and temperature; cool temperature downregulates the gene, high temperature causes an increase in its transcript level, and at intermediate temperatures, LDs upregulate and SDs silence FvTFL1 (Figure 1.3.2.1; Koskela et al. 2012; Rantanen et al. 2015). In the seasonal flowering $F$. vesca background, the decrease in FvTFL1 mRNA level concurs with upregulation of the meristem identity genes, $F$. vesca $A P 1$ ( FvAPl) and FUL (FvFUL), and results in flowering (Mouhu et al. 2009; Koskela et al. 2012; Rantanen et al. 2015).

FvTFL1 is regulated by the photoperiodic pathway through the action of $F$. vesca FT1 ( FvFT1) and $S O C 1$ ( $F v S O C 1$ ). Both genes are upregulated by LDs, and functional evidence from transgenic plants indicate that FvFT1 acts at least partially through upregulation of FvSOC1 (Mouhu et al. 2013). Overexpression of $\mathrm{FvSOC1}$ in seasonal flowering $F$. vesca background leads to upregulation of FvTFL1, resulting in repression of flowering, whereas the RNAi silencing of FvSOC1 leads to continuous flowering in LDs. Thus, activation of the photoperiodic FvFT1-FvSOC1 pathway represses flowering in seasonal flowering $F$. vesca accessions in LDs by upregulation of the floral repressor FvTFL1 (Koskela et al. 2012; Mouhu et al. 2013). Under SDs, however, FvFT1 is rapidly downregulated (Rantanen et al. 2014; Rantanen et al. 2015), whereas the downregulation of FvTFL1 and flower induction occur much slower (Heide and Sønsteby 2007; Koskela et al. 2012). Therefore, additional unknown factors are likely needed to to downregulate FvTFL1 in SDs.

Interestingly, altering FvTFL1 expression level in the seasonal flowering $F$. vesca background did not change patterns of vegetative development, i.e. runner and branch crown formation (Koskela et al. 2012). These results seem to be at odds with physiological studies, which have indicated that flowering and runner formation are almost mutually exclusive processes (reviewed in e.g. Hytönen and Elomaa 2011). However, this can be explained by the observations by Mouhu et al. (2013), who showed that overexpressing the photoperiodic pathway gene FvSOC1 results in increased runner production whereas silencing the gene promotes axillary bud development into branch crowns. The changes in FvSOCl expression also alter the expression of many gibberellin (GA) biosynthetic and signaling pathway genes, and GA is needed for the differentiation of axillary buds to runners (Hytönen et al. 2009; Mouhu et al. 2013). Thus, FvSOC1 and FvTFL1 are components of the photoperiodic pathway, in which FvTFL1 controls the onset of flowering and FvSOC1 regulates both flowering via FVTFL1 and aspects of vegetative development via the GA pathway.

Early physiological studies have suggested that inhibition of flowering and promotion of vegetative vigor in LD-grown strawberries could be caused by a hormone that is produced in leaves and transported to the shoot apex (Thompson and Guttridge 1959). The same workers also demonstrated that the effect of LDs could be mimicked by GA application (Thompson and Guttridge 1959; Guttridge and Thompson 1964). As the upregulation of FvSOC1 leads to upregulation of the GA pathway, and FvSOC1 is upregulated by FvFT1 (Mouhu et al. 2013), it can be speculated that the LD-induced mobile "hormone" could be FvFT1. The FvFT1 protein is likely produced in leaf 
vascular tissue and transported to the shoot apex, where it activates $F v S O C l$ and results in increased vegetative vigor. In seasonal flowering strawberries, the floral-promoting effect of FvFT1 is counteracted by increased FvTFL1 expression, which inhibits flowering (Koskela et al. 2012).
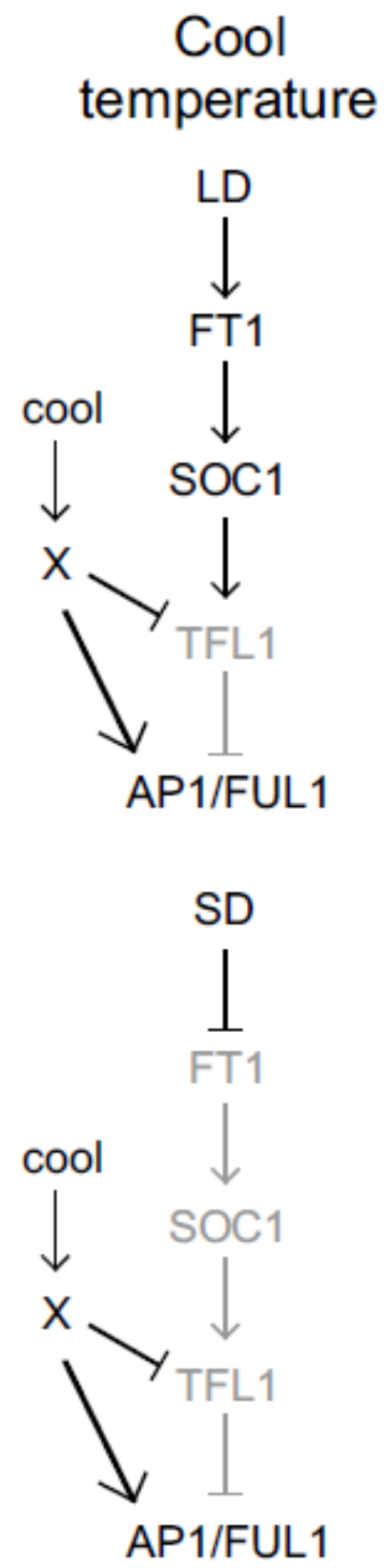
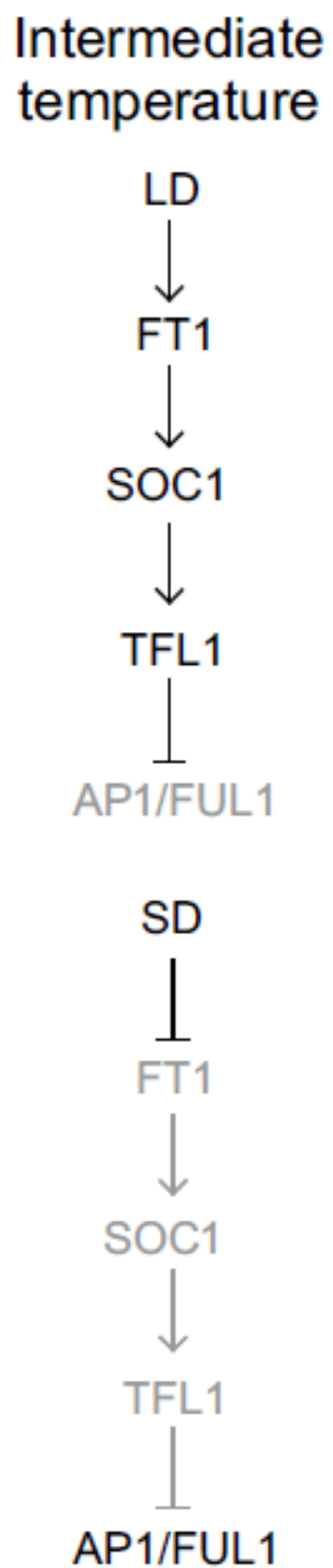

\section{Warm temperature}
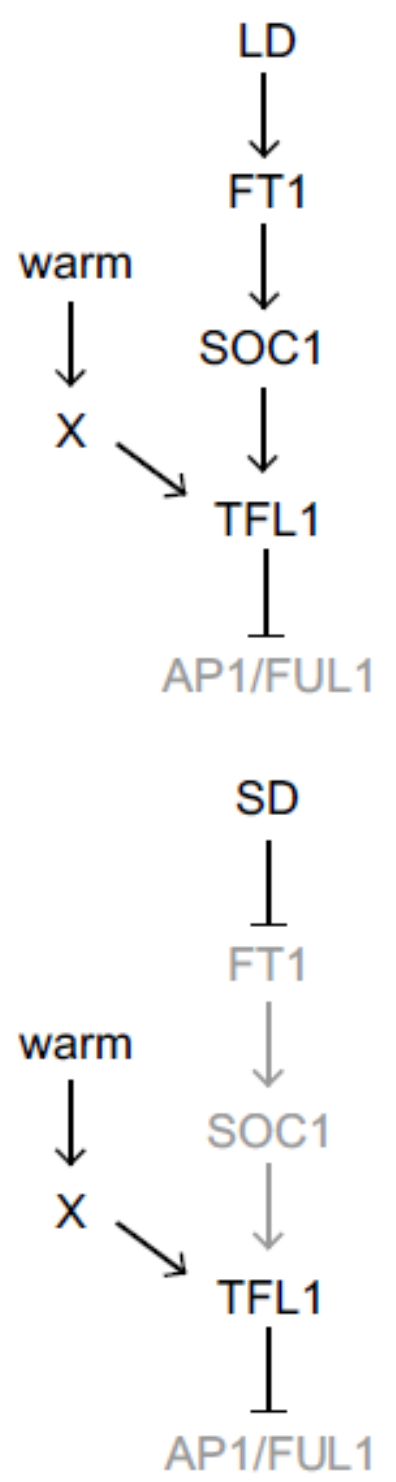

Figure 1.3.2.1. Diagram of environmentally regulated flowering pathways in woodland strawberry. The upper row depicts genetic pathways that are active (in black) or inactive (in gray) in LD conditions at cool, intermediate or warm temperature. The lower row depicts the activity of the pathways under SD conditions. Temperature regulates the expression of FvTFL1 and the meristem identity genes $F v A P 1$ and $F v F U L 1$ through unidentified genetic factors marked by ' $\mathrm{X}$ ' in the diagram.

In everbearing accessions with mutated FvTFL1, the photoperiodic FvFT1-FvSOC1 pathway is activated in LDs similarly to SD F. vesca accessions. However, the outcome of the pathway is reversed, as the mutation at FvTFL1 causes a frameshift and renders the protein product nonfunctional (Koskela et al. 2012). In everbearing accessions, the LD-dependent upregulation of the putative mobile floral promoter FvFT1 leads to upregulation of the meristem identity genes $F v A P 1$ and $F v F U L 1$ and causes early flowering (Koskela et al. 2012; Rantanen et al. 2014). A similar genetic basis for continuous flowering has been described in rose (Rosa $\times$ wichuriana), in which a retrotransposon insertion blocks TFL1 transcription (Iwata et al. 2012).

The temperature-regulated pathway in strawberry is not as well characterised as the photoperiodic 
pathway. However, functional data strongly suggests that FvTFL1 regulation has a central role in temperature-mediated responses. As described earlier, FvTFL1 expression responds to changes in temperature, with higher temperatures increasing the transcript level of the gene, whereas FvFT1 mRNA expression is reduced at high temperatures. Moreover, the upregulation of FvTFL1 by high temperature is independent of the activity of the photoperiodic $F v F T 1-F v S O C 1$ pathway, as high temperature upregulates FvTFL1 also in plants with silenced FvSOC1 (Rantanen et al. 2015). The factor that activates $F v T F L 1$ at high temperature remains unknown, but is a topic of active ongoing research. Thus, the ambient temperature regulated pathway in strawberries appears to be very different from the pathway described in Arabidopsis, in which the temperature regulation of FT controls flowering time (Bouché et al. 2016).

How exactly FvTFL1 represses flowering in the diploid strawberry has not been directly studied, but results from other species provide strong cues as to its mode of action. As discussed earlier, it has been demonstrated that Arabidopsis FT and TFL1 can compete for binding to the bZIP transcription factor FD expressed in the shoot apical meristem (Abe et al. 2005; Wigge et al. 2005). Studies in several distantly related plant species, including tomato (Pnueli et al. 2001) and rose (Randoux et al. 2014) have indicated that the same competitive mechanism is active in a wide range of plant species. Therefore, it is likely that the same dynamic balance of FT and TFL1 controls the downstream responses also in strawberry.

In addition to strawberries, TFL1 maintains the vegetative status of the meristems also in several other Rosaceous species, including apple (Flachowsky et al. 2012), pear (Freiman et al. 2012) and rose (Iwata et al. 2012). However, divergent spatial and temporal expression patterns of TFL1 homologs can bring about different phenological outcomes. For example, apple TFL1 (MdTFL1-2; Mimida et al. 2009) was recently described as having a role in limiting fruit set in apple trees with heavy fruit loads. In the study of Haberman et al. (2016), it was shown that variations in MdTFL1-2 expression level correlated with the amplitude of alternate bearing of different apple cultivars, and was related to different fruit loads on a tree. Since TFL1 seems to be a general floral repressor in Rosaceae, it is a target of active ongoing research. Studies in a Rosaceae model F. vesca are paving the way for molecular understanding of its regulation.

As discussed in Chapter 1.1.3, dormancy and dormancy release by chilling are important physiological events that have large effects on the next year's yield potential in strawberries. The molecular basis for these physiological responses have not been studied in detail in strawberries, but results from other Rosaceous species suggest that a group of DORMANCY-ASSOCIATED MADS (DAM; Bielenberg et al. 2008) transcription factors may contribute to the cessation and inhibition of growth in dormant perennial trees (Bielenberg et al. 2008; Saito et al. 2013). In peach, the loss of a cluster of six $D A M$ genes abolishes the response to dormancy-inducing conditions (Bielenberg et al. 2008), and the expression patterns of three of these genes in peach buds support a role in growth cessation and onset of dormancy ( $\mathrm{Li}$ et al. 2009). A similar trend in the seasonal expression patterns of $D A M$ genes have been described also in Japanese pear; the expression of $D A M$ genes increases during autumn and reaches the maximum level at the time of the deepest dormancy in November, after which $D A M$ expression is gradually reduced (Saito et al. 2013). Other studies have indicated that $D A M$ expression is likely regulated by CBF transcription factors, miRNAs, and epigenetic mechanisms (Leida et al. 2012; Niu et al. 2015; Saito et al. 2015). The onset of dormancy could be very well regulated by DAM transcription factors in strawberries as well; DAM expression level increases gradually as a response to SDs and cool temperature, after which there is a sudden drop in $D A M$ mRNA (Figure 1.3.2.2). 


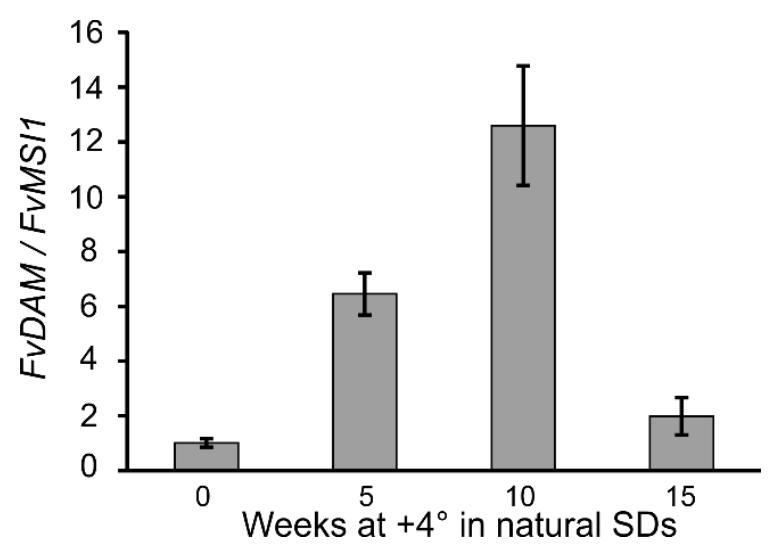

Figure 1.3.2.2. Accumulation of $F v D A M$ mRNA as a response to $4^{\circ} \mathrm{C}$ under natural SD conditions. Plants of the Norwegian vernalisation-requiring accession 'Alta' were grown in the mentioned conditions and shoot apex samples were collected at $0,5,10$ and 15 weeks. Error bars denote standard deviation between biological replicates $(n=3)$.

Given the vast distribution of $F$. vesca around the Northern Hemisphere, it is to be expected that the species contains a range of different environmental responses. Indeed, accessions collected from Southern Europe are able to upregulate $F v F T 1$ at shorter photoperiods than more Northern accessions, and they have shorter critical photoperiod for flower induction (S. Kymäläiinen, T. Toivainen and T. Hytönen, unpublished). Whether FvTFL1 or other flowering-time genes are differentially regulated in accessions of different latitudinal origins awaits further inspection.

\subsubsection{Genetics of flowering in the octoploid strawberry}

Recent studies in the octoploid strawberry have taken advantage of the genetic data gained from the work with the diploid strawberry. As described above, FvFT1 and FvSOCl are involved in the regulation of LD-dependent photoperiodic flowering in the diploid strawberry. Several independent reports (Nakajima et al. 2014; Nakano et al. 2015; Koskela et al. 2016) have shown that the octoploid strawberry homologue of $F T 1$ ( $F a F T 1)$ is expressed in leaf tissue exclusively in LD conditions. Moreover, the diurnal expression pattern of FaFT1 is similar to that of FvFT1 (Koskela et al. 2016), rendering support for the view that the two genes have the same LD-dependent function in the two species. The octoploid strawberry homolog of SOC1 (FaSOC1) mostly shows similar expression patterns to FvSOC1, although cultivar-dependent differences have also been reported; whereas Koskela et al. (2016) consistently found high levels of FaSOC1 expression only in LDs in the five studied cultivars, Nakano et al. (2015) were not able to detect such clear-cut differences between photoperiodic treatments in the Japanese cultivar Nyoho. Therefore, strawberry cultivars may have differences in the photoperiodic regulation of $\mathrm{FaSOCl}$ expression, but further experiments are needed to examine how these differences correlate with flowering time.

As FvTFL1 is a major regulator of flowering responses in the diploid strawberry, it has been of great interest to elucidate whether the octoploid strawberry homolog $(F a T F L 1)$ has a similar function as a floral repressor. In the diploid strawberry, FvTFL1 is photoperiodically regulated by the $F v F T 1-$ FvSOC1 pathway, with LDs activating the pathway and leading to repression of flowering through the upregulation of FvTFL1 (Koskela et al. 2012; Mouhu et al. 2013; Rantanen et al. 2014). At the gene expression level, similar responses to environmental conditions have been reported in several octoploid strawberry cultivars; FaTFL1 is activated in LDs and also by high temperature (Koskela et al. 2016). However, there are cultivar-dependent differences in FaTFL1 regulation, as some cultivars show age-dependent FaTFL1 downregulations independently of the photoperiod (Nakano et al. 2015; Koskela et al. 2016).

It was recently reported that FaTFL1 is indeed a floral repressor also in the octoploid strawberry, as silencing the gene in the SD cultivar Elsanta leads to flowering under LD conditions (Koskela et al. 2016). In line with the function of FvTFL1 in the diploid strawberry (Koskela et al. 2012), silencing FaTFL1 did not have any effect on vegetative development, nor did it change FaSOC1 expression (Koskela et al. 2016). Thus, regulation of flowering in diploid and octoploid strawberries 
appears to be conserved at the molecular level, at least in the case of the photoperiodic and temperature-regulated flowering pathways.

Although all the available data indicates that FaTFL1 is an important regulator of flowering in the octoploid strawberry, it is not the gene behind the everbearing character in cultivars. Several QTL mapping studies have shown that the everbearing trait resides in octoploid strawberry LGIV and also has a negative effect on runner formation (Gaston et al. 2013; Castro et al. 2015; Honjo et al. 2016), whereas FaTFL1 is located on LGVI and does not directly affect vegetative development (Koskela et al. 2016). A recent report by Perrotte et al. (2016a) suggested that the octoploid strawberry homolog of FT2 (FaFT2) is located within the QTL mapping window and could be a candidate for the observed phenotypes in everbearing octoploid strawberries. Indeed, the FaFT2 protein has been shown to possess all the hallmark features required for a floral-promoting function (Nakano et al. 2015). However, FaFT2 expression pattern suggests that FaFT2 acts downstream of FaAP1, and has a role in late stages of floral development (Nakano et al. 2015). This is also supported by the finding that its F. vesca ortholog FvFT2 exhibits the highest expression level in flower buds (Koskela et al. 2012). The identity of the gene causing the everbearing trait in the octoploid strawberry thus still remains a mystery. In any case, considering the data presented above, the gene must either silence FaTFL1 or act downstream of it.

Experiments using octoploid strawberry have also revealed a locus that affects flowering trait not characterized in the diploid strawberry. Longitudinal analysis of flowering data of everbearing strawberries has shown that there is a QTL on LGIII that affects the number of successive flowering phases and the intensity of flowering (Perrotte et al. 2016b). This QTL also has an effect on branch crown formation, and the authors suggested that genes related to the GA pathway might present good candidate genes for the QTL (Perrotte et al. 2016b). Since the number of branch crowns affects the number of inflorescences in strawberry (Hytönen et al. 2004), further studies are needed to test if the QTL on LGIII increases the intensity of flowering indirectly through increased branching.

\section{References}

Abe M, Kobayashi Y, Yamamoto S et al (2005) FD, a bZIP protein mediating signals from the floral pathway integrator FT at the shoot apex. Science 309:1052-1056

Albani MC, Coupland G (2010) Comparative analysis of flowering in annual and perennial plants. Curr Top Dev Biol 91:323-348

Andrés F, Coupland G (2012) The genetic basis of flowering responses to seasonal cues. Nat Rev Genet 13:627-639

Battey NH, Le Miére P, Tehranifar A et al (1998) Genetic and environmental control of flowering in strawberry. In: Cockshull KE, Gray D, Seymour GB, Thomas B (eds) Genetic and environmental manipulation of horticultural crops. CABI Publishing, Wallingford, UK, p 111-131

Bielenberg DG, Wang YE, Li Z et al (2008) Sequencing and annotation of the evergrowing locus in peach [Prunus persica (L.) Batsch] reveals a cluster of six MADS-box transcription factors as candidate genes for regulation of terminal bud formation. Tree Genet Genomes 4:495-507

Bouché F, Lobet G, Tocquin P et al (2016) FLOR-ID: an interactive database of flowering-time gene networks in Arabidopsis thaliana. Nucl Acids Res 44(D1):D1167-D1171

Bradford E, Hancock JF, Warner RM (2010) Interactions of temperature and photoperiod determine expression of repeat flowering in strawberry. J Amer Soc Hort Sci 135:102-107

Brown T, Wareing PF (1965) The genetical control of the everbearing habit and three other 
characters in varieties of Fragaria vesca. Euphytica 14:97-112

Böhlenius H, Huang T, Charbonnel-Campaa L et al (2006). CO/FT regulatory module controls timing of flowering and seasonal growth cessation in trees. Science 312:1040-1043

Camacaro PME, Camacaro GJ, Hadley P et al (2002) Pattern of growth and development of the strawberry cultivars Elsanta, Bolero, and Everest. J Amer Soc Hort Sci 127:901-907

Castro P, Bushakra JM, Stewart P et al (2015) Genetic mapping of day-neutrality in cultivated strawberry. Mol Breed 35:79

Corbesier L, Vincent C, Jang S et al (2007) FT protein movement contributes to long-distance signaling in floral induction of Arabidopsis. Science 316:1030-1033

Dale A, Luby JJ, Hancock JF (2002) Breeding dayneutral strawberries for Northern North America. Acta Hort 567:133-136

Darrow GM (1966) The strawberry. Holt, Rinehart and Winston, NY, USA

Darrow GM, Waldo GF (1934) Responses of strawberry varieties and species to duration of the daily light period. US Dept Agr Tech Bull 453

Durner EF, Barden JA, Himelrick DG et al (1984) Photoperiod and temperature effects on flower and runner development in day-neutral, Junebearing and everbearing strawberries. J Am Soc Hort Sci 109:396-400

Flachowsky H, Szankowski I, Waidmann S et al (2012) The MdTFL1 of apple (Malus $\times$ domestica Borkh.) reduces vegetative growth and generation time. Tree Physiol 32:1288-1301

Footit S, Douterelo-Soler I, Clay H et al (2011) Dormancy cycling in Arabidopsis seeds is controlled by seasonally distinct hormone-signaling pathways. Proc Nat Acad Sci 108:20236-20241

Freiman A, Shlizerman L et al (2012) Development of a transgenic early flowering pear (Pyrus communis L.) genotype by RNAi silencing of PcTFL1-1 and PcTFL1-2. Planta 235:1239-1251

Gaston A, Perrotte J, Lercetau-Köhler E et al (2013) PFRU, a single dominant locus regulates the balance between sexual and asexual plant reproduction in cultivated strawberry. J Exp Bot 64:18371848

Guttridge CG (1985) Fragaria $\times$ ananassa. In: Halevy A (ed) CRC Handbook of Flowering, Volume III. CRC Press Inc. Boca Raton, FL, p 16-33

Hanano S, Goto K (2011) Arabidopsis TERMINAL FLOWER1 is involved in the regulation of flowering time and inflorescence development through transcriptional regulation. Plant Cell 23:3172-3184

Hayama R, Yokoi S, Tamaki S et al (2003) Adaptation of photoperiodic control pathways produces short-day flowering in rice. Nature 422:719-722.

Heide OM (1977) Photoperiod and temperature interactions in growth and flowering of strawberry. Physiol Plant 40:21-26

Heide OM, Sønsteby A (2007) Interactions of temperature and photoperiod in the control of flowering of latitudinal and altitudinal populations of wild strawberry (Fragaria vesca). Physiol Plant 130:280-289 
Hempel FD, Weigel D, Mandel MA et al (1997) Floral determination and expression of floral regulatory genes in Arabidopsis. Development 124:3845-385

Ho WWH, Weigel D (2014) Structural features determining flower-promoting activity of Arabidopsis FLOWERING LOCUS T. Plant Cell 26:552-564

Honjo M, Nunome T, Kataoka S et al (2015) Simple sequence repeat markers linked to the everbearing flowering gene in long-day and day-neutral cultivars of the octoploid cultivated strawberry Fragaria x ananassa. Euphytica 209:291-303

Hytönen T, Palonen P, Mouhu K et al (2004) Crown branching and cropping potential in strawberry (Fragaria $\times$ ananassa Duch.) can be enhanced by daylength treatments. J Hort Sci Biotech 79:466471

Iwata H, Gaston A, Remay A et al (2012) The TFL1 homologue $K S N$ is a regulator of continuous flowering in rose and strawberry. Plant J 69:116-125

Jonkers H (1965) On the flower formation, the dormancy and the early forcing of strawberries. Mededlingen Landbouwhogeschool Wageningen 65:1-71

Kobayashi Y, Kaya H, Goto K, et al (1999) A pair of related genes with antagonistic roles in mediating flowering signals. Science 286:1960-1962

Koornneef M, Hanhart CJ, van der Veen JH (1991) A genetic and physiological analysis of late flowering mutants in Arabidopsis thaliana. Mol Gen Genet 229:57-66

Koskela EA, Mouhu K, Albani MC et al (2012) Mutation in TERMINAL FLOWER1 reverses the photoperiodic requirement for flowering in the wild strawberry Fragaria vesca. Plant Physiol 159:1043-1054

Koskela E, Sønsteby A, Flachowsky $\mathrm{H}$ et al (2016) TERMINAL FLOWER1 is a breeding target for a novel everbearing trait and tailored flowering responses in cultivated strawberry (Fragaria $\times$ ananassa Duch.). Plant Biotech J. doi: 10.1111/pbi.12545

Kotoda N, Iwanami H, Takahashi S and Abe K (2006) Antisense expression of MdTFL1, a TFL1like gene, reduces the juvenile phase in apple. J Amer Soc Hort Sci 131(1):74-81.

Kumar SV, Wigge PA (2010) H2A.Z-containing nucleosomes mediate the thermosensory response in Arabidopsis. Cell 140:136-147

Kumar SV, Lucyshyn D, Jaeger KE et al (2012) Transcription factor PIF4 controls the thermosensory activation of flowering. Nature 484:242-246

Le Miére P, Hadley P, Darby J et al (1998) The effect of thermal environment, planting date and crown size on growth, development and yield of Fragaria x ananassa Duch. cv. Elsanta. J Hort Sci Biotech 73(6):786-795

Lee JH, Ruy HS, Chung KS et al (2013) Regulation of temperature-responsive flowering by MADS-box transcription factor repressors. Science 342:628-632

Leida C, Conesa A, Llácer $\mathrm{G}$ et al (2012) Histone modifications and expression of DAM6 gene in peach are modulated during bud dormancy release in a cultivar dependent manner. New Phytol 193:67-80 
Li Z, Reighard GL, Abbott AG et al (2009) Dormancy-associated MADS genes from the $E V G$ locus of peach [Prunus persica (L.) Batsch] have distinct seasonal and photoperiodic expression patterns. J Exp Bot 60:3521-3530

Lieten F (1997) Effects of chilling and night-break treatment on greenhouse production of 'Elsanta'. Acta Hort 439:633-640

Lin MK, Belanger H, Lee YJ et al (2007) FLOWERING LOCUS T protein may act as the longdistance florigenic signal in the cucurbits. Plant Cell: 19:1488-1506

Manakasem Y, Goodwin PB (2001) Responses of dayneutral and Junebearing strawberries to temperature and daylength. J Hort Sci Biotech 76:629-635

Mimida N, Kotoda N, Ueda T et al (2009) Four TFL1/CEN-like genes on distinct linkage groups show different expression patterns to regulate vegetative and reproductive development in apple (Malus $\times$ domestica Borkh.). Plant Cell Physiol 50(2):394-412

Mouhu K, Hytönen T, Folta K et al (2009) Identification of flowering genes in strawberry, a perennial SD plant. BMC Plant Biol 9:122

Mouhu K, Kurokura T, Koskela EA et al (2013) The Fragaria vesca homolog of SUPPRESSOR OF OVEREXPRESSION OF CONSTANS1 represses flowering and promotes vegetative growth. Plant Cell 25: 3296-3310

Nakano J, Higuchi Y, Yoshida Y et al (2015) Environmental responses of the FT/TFL1 gene family and their involvement in flower induction in Fragaria $\times$ ananassa. J Plant Physiol 177:60-66

Nakano Y, Higuchi Y, Sumimoto K et al (2013) Flowering retardation by high temperature in chrysanthemums: involvement of FLOWERING LOCUS T-LIKE 3 gene repression. J Exp Bot 64:909-920

Nakajima R, Otagaki S, Yamada K et al (2014) Molecular cloning and expression analyses of FaFT, $F a T F L$, and FaAPl genes in cultivated strawberry: their correlation to flower bud formation. Biol Plant 58:641-648

Nishikawa F, Endo T, Shimada T et al (2007) Increased CiFT abundance in the stem correlates with floral induction by low temperature in Satsuma mandarin (Citrus unshiu Marc.). J Exp Bot 58:3915-3927

Nishiyama M, Kanahama K (2002) Effects of temperature and photoperiod on flower bud initiation of day-neutral and everbearing strawberries. Acta Hort 567:253-255

Niu Q, Li J, Cai D et al (2016) Dormancy-associated MADS-box genes and microRNAs jointly control dormancy transition in pear (Pyrus pyrifolia white pear group) flower bud. J Exp Bot 67:239-257

Perrotte J, Gaston A, Potier A et al (2016a) Narrowing down the single homoeologous FaPFRU locus controlling flowering in cultivated octoploid strawberry using a selective mapping strategy. Plant Biotechnol J 14:2176-2189

Perrotte J, Guédon Y, Gaston A et al (2016b) Identification of successive flowering phases highlights a new genetic control of the flowering pattern in strawberry. $\mathrm{J}$ Exp Bot doi:

$10.1093 / \mathrm{jxb} / \mathrm{erw} 326$ 
Pnueli L, Gutfinger T, Hareven D et al (2001) Tomato SP-interacting proteins define a conserved signaling system that regulates shoot architecture and flowering. Plant Cell 13:2687-2701

Posé D, Verhage L, Ott F et al (2013) Temperature-dependent regulation of flowering by antagonistic FLM variants. Nature 503:414-417

Randoux M, Davière JM, Jeauffre J et al (2014) RoKSN, a floral repressor, forms protein complexes with RoFD and RoFT to regulate vegetative and reproductive development in rose. New Phytol 202:161-173

Rantanen M, Kurokura T, Jiang P et al (2015) Strawberry homologue of TERMINAL FLOWER1 integrates photoperiod and temperature signals to inhibit flowering. Plant J 82:163-173

Rantanen M, Kurokura T, Mouhu K et al (2014) Light quality regulates flowering in FvFT1/FvTFL1 dependent manner in the woodland strawberry Fragaria vesca. Front Plant Sci 5, p 271

Saito T, Bai S, Imai T et al (2015) Histone modification and signalling cascade of the dormancyassociated MADS-box gene, PpMADS13-1, in Japanese pear (Pyrus pyrifolia) during endodormancy. Plant Cell Env 38:1157-1166

Saito T, Bai S, Ito A et al (2013) Expression and genomic structure of the dormancy-associated MADS box genes MADS13 in Japanese pears (Pyrus pyrifolia Nakai) that differ in their chilling requirement for dormancy release. Tree Physiol 33:654-667

Samach A, Onouchi H, Gold SE et al (2000) Distinct roles of CONSTANS target genes in reproductive development in Arabidopsis. Science 288:1613-1616.

Shannon S, Meeks-Wagner DR (1991) A mutation in the Arabidopsis TFL1 gene affects inflorescence meristem development. Plant Cell 3:877-892

Shulaev V, Sargent DJ, Crowhurst RN et al (2011) The genome of woodland strawberry (Fragaria vesca). Nat Genet 43:109-116

Sønsteby A, Heide OM (2006) Dormancy relations and flowering of the strawberry cultivars Korona and Elsanta as influenced by photoperiod and temperature. Scientia Hort 110:57-67

Sønsteby A, Heide OM (2007a) Long-day control of flowering in everbearing strawberries. J Hort Sci Biotech 82:875-884

Sønsteby A, Heide OM (2007b)

Sønsteby A, Heide OM (2008a) Long-day rather than autonomous control of flowering in the diploid everbearing strawberry Fragaria vesca ssp. semperflorens. J Hort Sci Biotech 83:360-366

Sønsteby A, Heide OM (2008b) Flowering physiology of populations of Fragaria virginiana. J Hort Sci Biotech 83: 641-647

Sønsteby A, Heide OM (2011) Environmental regulation of dormancy and frost hardiness in Norwegian populations of wood strawberry (Fragaria vesca L.). Eur J Plant Sci Biotechn 5(1): 42 48

Sønsteby A, Nes A (1998) Short days and temperature effects on growth and flowering in strawberry (Fragaria x ananassa Duch.). J Hort Sci Biotech 73:730-736 
Teper-Bamnolker P, Samach S (2005) The flowering integrator FT regulates SEPALLATA3 and FRUITFULL accumulation in Arabidopsis leaves. Plant Cell 17:2661-2675

Tränkner C, Lehmann S, Hoenicka H et al (2010) Over-expression of an FT-homologous gene of apple induces early flowering in annual and perennial plants. Planta 232:1309-1324

Turck F, Fornara F, Coupland G (2008) Regulation and identity of florigen: FLOWERING LOCUS T moves center stage. Ann Rev Plant Biol 59:573-594

Verheul MJ, Sønsteby A, Grimstad SO (2007) Influences of day and night temperatures on flowering of Fragaria x ananassa Duch., cvs. Korona and Elsanta, at different photoperiods. Sci Hort 112: 200-206

Wigge PA, Kim MC, Jaeger KE et al (2005) Integration of spatial and temporal information during floral induction in Arabidopsis. Science 309: 1056-1059.

\section{Figure captions}

Figure 1.1.1. Plant structure and typical seasonal growth cycle of strawberries grown in temperate zone. During the summer months, strawberries grow vegetatively and axillary buds produce runners, whereas in autumn, young axillary buds differentiate into branch crowns. Floral induction occurs in autumn, and apical meristems of main and branch crowns develop into inflorescence meristems. Inflorescence development is completed in the following spring and summer when plants flower and produce fruits. The axillary buds that were too young to be induced to flower the preceding autumn (highlighted with black rectangles) grow out as new branch crowns, thus completing the perennial life cycle.

Figure 1.1.1.1. Average cumulative number of runners at different temperatures. Runner-propagated plants of seasonal flowering $F$. vesca were grown in $\mathrm{LDs}$ at either $11^{\circ} \mathrm{C}$ or $18^{\circ} \mathrm{C}$ for five weeks. Error bars denote the standard error of the mean $\left(\mathrm{n}=16\right.$ and 10 for $11^{\circ} \mathrm{C}$ and $18^{\circ} \mathrm{C}$ treatments, respectively).

Figure 1.3.2.1. Diagram of environmentally regulated flowering pathways in woodland strawberry. The upper row depicts genetic pathways that are active (in black) or inactive (in gray) in LD conditions at cool, intermediate or warm temperature. The lower row depicts the activity of the pathways under SD conditions. Temperature regulates the expression of FvTFL1 and the meristem identity genes $F v A P 1$ and $F v F U L 1$ through unidentified genetic factors marked by ' $\mathrm{X}$ ' in the diagram.

Figure 1.3.2.2. Accumulation of $F v D A M$ mRNA as a response to $4{ }^{\circ} \mathrm{C}$ under natural SD conditions. Plants of the Norwegian vernalisation-requiring accession 'Alta' were grown in the mentioned conditions and shoot apex samples were collected at 0, 5, 10 and 15 weeks. Error bars denote standard deviation between biological replicates $(n=3)$. 